
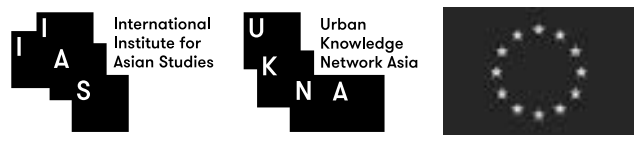

\title{
About the Three UKNA Volumes
}

This book is part of a series of three edited volumes published in the Asian Cities series of Amsterdam University Press and the International Institute for Asian Studies, and coordinated by editors from the Urban Knowledge Network Asia (UKNA):

- Volume 1: Ideas of the City in Asian Settings

- Volume 2: Cities in Asia by and for the People

- Volume 3: Future Challenges of Cities in Asia

The UKNA was established in 2012 with a grant from the European Union's Marie Curie Actions International Research Staff Exchange Scheme (IRSES) mobility scheme to bring together scholars from thirteen universities and planning institutions in greater China, India, Europe and the United States around collaborative research on urbanization in Asia ${ }^{1}$. Since then the network has expanded to include also other partners in Northeast Asia, South Asia and Southeast Asia, and today represents a broad coalition of scholars and practitioners united by a common objective of promoting "human flourishing and the creative production of urban space". The focus is on cities across Asia, as well as cities beyond Asia in comparative perspective.

UKNA seeks to influence scholarship on cities as well as on policy by contributing insights that put people at the center of urban governance and development strategies. The emphasis is on immediate problem solving as well as the identification of long term, transformative processes that increase

1 The original UKNA partners that participated in the research staff exchanges covered by the IRSES grant comprised: Ambedkar University Delhi (India); College of Architecture and Urban Planning, Beijing University of Technology (China); China Academy of Urban Planning and Design (China); CEPT University (India); Centre for Urban and Regional Studies, Shanghai Academy of Social Sciences (China); Development Planning Unit, University College London (UK); Ecole Nationale Supérieure d'Architecture de Paris-Belleville (France); Department of Architecture, Hong Kong University (Hong Kong SAR); International Institute for Asian Studies, Leiden (the Netherlands); Indian Institute for Human Settlements (India); School of Architecture, Tianjin University (China); Faculty of Architecture and the Built Environment, Delft University of Technology (the Netherlands); and Sol Price School of Public Policy, University of Southern California (USA). 
the scope for the active engagement of people in the creative production and shaping of their cities - particularly in the realm of knowledge. UKNA seeks to develop a new, multi-disciplinary body of knowledge on cities, one that goes beyond the 'scientific' approaches transmitted in the curricula of classic urban studies programs. It seeks to encompass alternative epistemologies of the city rooted in everyday urban life. These epistemologies seek to embrace non-Western knowledge and traditions and the contributions of a wide range of methods of investigation in the humanities, social sciences and natural sciences.

These three edited volumes represent the output of urban scholars who participated in the UKNA mobility schemes from 2012 to 2016 , as well as other scholars who were invited to contribute to the series through separate calls for papers.

The diversity of essays in these volumes represents the diversity of the UKNA itself, which brings together young scholars, including $\mathrm{PhD}$ candidates and post-doctoral researchers, as well as established contributors from over twenty countries and from a multiplicity of backgrounds and interests. The wide range of topics covered in these three volumes, reflecting crossdisciplinary perspectives and different kinds of expertise, embodies the "diversity of ways to read the city" that UKNA propagates.

The three volumes would not have been possible without the generous support of the European Union in making possible the exchanges of scholars that were at the basis of the collaborative research that led to many of the book chapters. In addition, UKNA wishes to acknowledge the following institutions and UKNA partners for their financial support and initiatives in bringing together the chapter authors and editors: the Rockefeller Foundation's Bellagio Center; the Asia Research Institute of the National University of Singapore; the Bartlett Development Planning Unit of University College London; the Ecole Nationale Supérieure d'Architecture of Paris-Belleville; the Faculty of Architecture and the Built Environment of Delft University of Technology; CEPT University; the City Government of Pingyao, Shanxi Province, China; and the International Institute for Asian Studies in Leiden.

Paul Rabé, D.P.P.D.

UKNA Coordinator and Editor, Asian Cities book series 